\title{
RESPOSTA DA ALFACE TIPO AMERICANA A DOSES E ÉPOCAS DE APLICAÇÃO DE MOLIBDÊNIO EM CULTIVO DE INVERNO
}

\author{
Response of crisphead lettuce to rates and application times of molybdenum in winter planting
}

\author{
Geraldo Milanez de Resende ${ }^{1}$, Jony Eishi Yuri³ ${ }^{3}$ José Hortêncio Mota ${ }^{4}$, \\ Rovilson José de Souza ${ }^{2}$
}

\begin{abstract}
RESUMO
Foram conduzidos três experimentos no período de maio a julho de 2002, no município de Três Pontas - MG, com o objetivo de avaliar a influência de doses de molibdênio sobre a produtividade da alface tipo americana. Utilizou-se o delineamento de blocos ao acaso com cinco doses de molibdênio $(0,35,1 ; 70,2 ; 105,3$ e 140,4 g/ha) e 4 repetições, aplicadas via foliar em três diferentes épocas $(14,21$ e 28 dias após o transplantio). Para matéria fresca total, constataram-se efeitos quadráticos nas quais as doses de 83,7; 77,2 e $81,9 \mathrm{~g} /$ ha de molibdênio proporcionaram as maiores produtividades aos 14,21 e 28 dias após o transplantio. A maior produtividade de matéria fresca comercial foi obtida com a aplicação aos 28 dias após o transplantio na dose de 77,5 g/ha de molibdênio. O maior comprimento de caule foi obtido com a dose de $85,6 \mathrm{~g} / \mathrm{ha}$ de molibdênio. Não se observou efeitos significativos dos tratamentos para circunferência da cabeça comercial.
\end{abstract}

Termos para indexação: Lactuca sativa, produtividade, comprimento do caule, circunferência da cabeça comercial.

\section{ABSTRACT}

With the objective of evaluating the influence of molybdenum doses on yield in crisphead lettuce, three experiments were carried out at Três Pontas, State of Minas Gerais, Brazil, from May to July of 2002. The experimental design was in randomized blocks outline with five molybdenum doses $(0.0,35.1,70.2,105.3$ and $140.4 \mathrm{~g} / \mathrm{ha})$ and four replicates, applied through foliar via in three different times $(14,21$ and 28 days after transplanting). For total fresh matter one verified quadratic effects in which doses of 83.7, 77.2 and $81.9 \mathrm{~g} / \mathrm{ha}$ of molybdenum showed the highest yield at 14, 21, and 28 days after transplanting. The highest yield for commercial fresh matter showed the application at 28 days after transplanting in the dose of $77.5 \mathrm{~g} / \mathrm{ha}$ of molybdenum. The largest stem length was obtained with the dose of $85.6 \mathrm{~g} / \mathrm{ha}$ of molybdenum. No significant effects of the treatments for commercial head circumference were observed.

Index terms: Lactuca sativa, yield, stem length, commercial head circumference.

\section{(Recebido em 9 de novembro de 2006 e aprovado em 13 de abril de 2007)}

\section{INTRODUÇÃO}

A alface (Lactuca sativa L.) é uma hortaliça mundialmente conhecida, e por ser consumida crua conserva melhor suas propriedades nutritivas, apresenta boa fonte de vitaminas, sais minerais e baixo valor energético (HAMASAKI et al., 2000).

A despeito do grande aumento no consumo de adubos foliares no País, não se encontram na literatura brasileira pesquisas conclusivas que dêem respaldo agronômico e econômico, justificando o aumento do seu uso (FAQUIN, 1997). A propaganda e a agressividade comercial fizeram com que esta prática se adiantasse à pesquisa. De acordo com Rosolem \& Boaretto (1987), as recomendações de uso de adubação foliar são feitas de forma empírica, sem embasamento experimental, supondo, portanto, que não surtam os efeitos desejados ou esperados de aumento de produção.

Dentre os micronutrientes aqueles que mais afetam o desenvolvimento da alface quando em níveis deficientes são o cobre, o molibdênio e o boro (FERREIRA et al., 1993).

Nos sistemas biológicos, o molibdênio é constituinte de pelo menos cinco enzimas catalisadoras de reações. Três destas enzimas (redutase do nitrato, nitrogenase e oxidase do sulfito) são encontradas em plantas (GUPTA \& LIPSETT, 1981). A função mais importante do molibdênio nas plantas está relacionada com o metabolismo do nitrogênio. Esta função está ligada à ação ou ativação enzimática, principalmente das enzimas nitrogenase e redutase do nitrato (DECHEN et al., 1991).

1Doutor - Embrapa Semi-Árido - Cx. P. 23 - 56302-970 - Petrolina, PE - gmilanez@cpatsa.embrapa.br

2Doutor - Departamento de Agricultura/DAG - Universidade Federal de Lavras/UFLA - Cx. P. 3037 - 37200-000 - Lavras, MG - rovilson@ufla.b ${ }^{3}$ Doutor - Universidade Vale do Rio Verde/UNINCOR - Avenida Castelo Branco, 82 - 37410-000 - Três Corações, MG - jonyyuri@uol.com.br ${ }^{4}$ Doutor - Departamento de Ciências Agrárias - Centro Universitário de Dourados - Cx. P. 533-79804-970 - Dourados, MS - hortenciomota@terra.com.br 
Uma resposta diferencial entre espécies a uma maior disponibilidade de molibdênio tem sido relatada, sendo de acordo com Malavolta \& Kliemann (1985) encontrada alta resposta em alface, brócolos, beterraba, couve-flor, espinafre e repolho. Respostas positivas à adubação com este nutriente têm sido relatadas com várias culturas, em diferentes países (GUPTA \& LIPSETT, 1981). Entre as hortaliças, couve-flor, brócolis, alface, beterraba, espinafre europeu, nabo e tomateiro se destacam como as culturas mais exigentes (CASTELLANE et al., 1991).

Em alface, os sintomas de deficiência de molibdênio começam a aparecer nas folhas amadurecidas que não se desenvolvem bem, permanecendo ovaladas e de cor verdeamarela pálida e mostrando textura semelhante à de papel. Em plantas bem nutridas com nitrato, os sintomas de deficiência de molibdênio assemelham-se aos de nitrogênio. Recomendam-se pulverizar as plantas na sementeira com solução de $0,05 \%$ de molibdato de amônio ou de sódio ou com o produto comercial Cofermol (SONNENBERG, 1998). Segundo Kaiser et al. (2005) pulverizações foliares com molibdênio são efetivas nas correções da deficiência do micronutriente.

No Brasil, poucas são as pesquisas realizadas sobre os efeitos do fornecimento isolado de molibdênio nas produções de oleráceas. Ao que parece, exceto para a espécie Phaseolus vulgaris L., que abrange o feijão para produção de grãos e o feijão-de-vagem, os trabalhos publicados envolvendo o uso de molibdênio em oleráceas são muito raros (CASTELLANE et al., 1991).

Respostas da cultura de alface ao fornecimento de $780 \mathrm{~g} /$ ha de molibdênio via solo, na forma de molibdato de sódio, promovendo um aumento médio de $31 \%$ na produtividade comercial da cultura foram constatados por Fontes et al. (1982), assim como Zito et al. (1994) verificaram um aumento de $24,1 \%$ na produção comercial de alface com a aplicação de molibdênio em meio hidropônico.

Com o incremento das doses de molibdênio, em função das épocas de aplicação, Yuri et al. (2004), verificaram efeitos quadráticos para a matéria fresca comercial, tendo as doses de 236; 212 e $229 \mathrm{~g} / \mathrm{ha}$ de molibdênio proporcionado os maiores rendimentos comerciais quando o nutriente foi aplicado aos 14, 21 e 28 dias, respectivamente.

A carência de informações sobre este micronutriente na cultura da alface tipo americana justificou o presente trabalho, que objetivou avaliar diferentes doses e épocas de aplicação de molibdênio na produtividade da alface tipo americana, em cultivo de inverno no sul de Minas Gerais.

\section{MATERIAL E MÉTODOS}

Foram conduzidos três experimentos distintos no período de maio a julho de 2002, no município de Três Pontas - MG, sul de Minas Gerais, a uma altitude de $855 \mathrm{~m}$, situado a $21^{\circ} 22^{\prime} 00^{\prime \prime}$ de latitude sul e $45^{\circ} 30$ ' $45^{\prime}$ ' de longitude oeste (IBGE, 2005). O tipo de solo predominante na área é classificado como Latossolo Vermelho Distroférrico de textura argilosa (EMBRAPA, 1999). A análise do solo onde foi instalado os experimentos apresentou as seguintes características químicas: $\mathrm{K}=60,0 \mathrm{mg} \mathrm{dm}^{-3} ; \mathrm{P}=58,0 \mathrm{mg} \mathrm{dm}^{-}$ 3. $\mathrm{Ca}=3,8 \mathrm{cmol}_{\mathrm{c}} \mathrm{dm}^{-3} ; \mathrm{Mg}=0,9 \mathrm{cmol}_{\mathrm{c}} \mathrm{dm}^{-3} ; \mathrm{Al}=0,0 \mathrm{cmol}_{\mathrm{c}}$

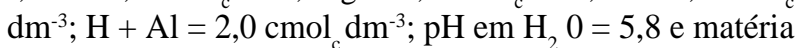
orgânica $=2,3$ dag $\mathrm{kg}^{-1}$.

Cada experimento foi conduzido em delineamento de blocos ao acaso, com cinco doses de molibdênio $(0,35,1$; 70,$2 ; 105,3$ e 140,4 g/ha) e quatro repetições, utilizando como fonte o molibdato de sódio ( $39 \%$ de molibdênio). Os experimentos diferiram quanto à época de aplicação foliar (14, 21 e 28 dias após o transplantio). As aplicações foliares foram realizadas com pulverizador manual com $4 \mathrm{~L}$ de capacidade em máxima pressão, gastando-se $300 \mathrm{~L}$ de calda por hectare.

As parcelas experimentais constituíram-se de canteiros com quatro linhas de $2,1 \mathrm{~m}$ de comprimento espaçadas de $0,30 \mathrm{~m}$, sendo entre plantas de $0,35 \mathrm{~m}$. As linhas centrais formaram a área útil, retirando-se duas plantas em cada extremidade. Os canteiros em número de dois foram cobertos por estruturas de proteção (túnel alto - 2,0 m de altura). A adubação de plantio foi baseada na análise de solo e constou de $1700 \mathrm{~kg} / \mathrm{ha}$ de formulado N$\mathrm{P}_{2} \mathrm{O}_{5}-\mathrm{K}_{2} \mathrm{O}$ (04-14-08) e $1000 \mathrm{~kg} / \mathrm{ha}$ de superfosfato simples. As adubações de cobertura foram realizadas através de fertirrigações diárias até 3 dias antes da colheita, totalizando $40 \mathrm{~kg} / \mathrm{ha}$ de $\mathrm{N}$ e $85 \mathrm{~kg} / \mathrm{ha}$ de $\mathrm{K}_{2} \mathrm{O}$, utilizando como fontes uréia e cloreto de potássio. O transplantio das mudas com 25 dias de semeadura foi feito em 15/05/2002, irrigando-se diariamente, sendo a cultura conduzida sob "mulching" e os demais tratos culturais os comuns à cultura.

As colheitas foram feitas em 17/07/2002 sendo avaliadas a matéria fresca total e comercial (g/planta); circunferência da cabeça comercial e comprimento do caule (cm). Os dados foram submetidos à análise de variância conjunta dos experimentos (épocas de aplicação), sendo as médias comparadas pelo teste de Tukey para épocas de aplicação e regressão polinomial para doses, ao nível de $5 \%$ de probabilidade.

\section{RESULTADOS E DISCUSSÃO}

Os resultados evidenciaram efeitos significativos independentes para as doses de molibdênio e época de 
aplicação, assim como para a interação entre estes fatores, variando com as características avaliadas.

No que se refere à matéria fresca total, verificou-se interação entre os fatores estudados $\left(\mathrm{F}_{(8,42)}=3,01\right.$; $\mathrm{P}<0,00929$ ). Para a aplicação aos 14, 21 e 28 dias após o transplantio constataram-se efeitos quadráticos nas quais as doses de 83,7; 77,2 e 81,9 g/ha de molibdênio proporcionaram as maiores produtividades (Figura 1). Resultados estes semelhantes aos obtidos por Resende et al. (2005), que observaram para aplicação aos 21 dias após o transplantio, que a dose de $87,4 \mathrm{~g} /$ ha de molibdênio promoveu o maior ganho em termos de rendimento de matéria fresca total, em condições de semeadura de verão. Yuri et al. (2004), também constataram que molibdênio proporcionou maior matéria fresca total, sendo superior em $15,2 \%$ à testemunha sem aplicação, no entanto, com maior dose, provavelmente em função dos atributos químicos do solo e da época em que foi realizado o plantio.

Comportamento similares foram observados para matéria fresca comercial onde observaram-se efeitos significativos da interação doses versus épocas de aplicação $\left(\mathrm{F}_{(8,42)}=4,04 ; \mathrm{P}<0,00151\right)$. Com o incremento das doses de molibdênio em função das épocas de aplicação (Figura 2), verificaram-se efeitos quadráticos tendo as doses de 77,0; 82,6 e 77,5 g/ha de molibdênio proporcionado as maiores retornos aos 14, 21 e 28 dias após o transplantio, respectivamente.

Verifica-se pela Figura 2 que as épocas de aplicação apresentaram pontos de máxima produtividade de magnitudes semelhantes com pequenas variações entre doses, onde a aplicação aos 28 dias após o transplantio na dose estimada pela equação proporcionou maior matéria fresca com 553,4 g/planta, comparativamente aos 21 dias (516,9 g/planta) e aos 14 dias (540,2 g/planta). Ainda, quando se analisa o fator época isoladamente verificou-se que a aplicação aos 28 dias (501,6 g/planta) diferiu significativamente da aplicação aos 21 dias (472,5 g/planta) e 14 dias após o transplantio (470,4 g /planta), que não apresentaram diferenças entre si.

Nesse contexto, sugere-se a aplicação do molibdênio aos 28 dias após o transplantio como a época mais adequada para obtenção de maior matéria fresca comercial. Resende et al. (2005), verificaram efeitos quadráticos para matéria fresca comercial, tendo a dose de

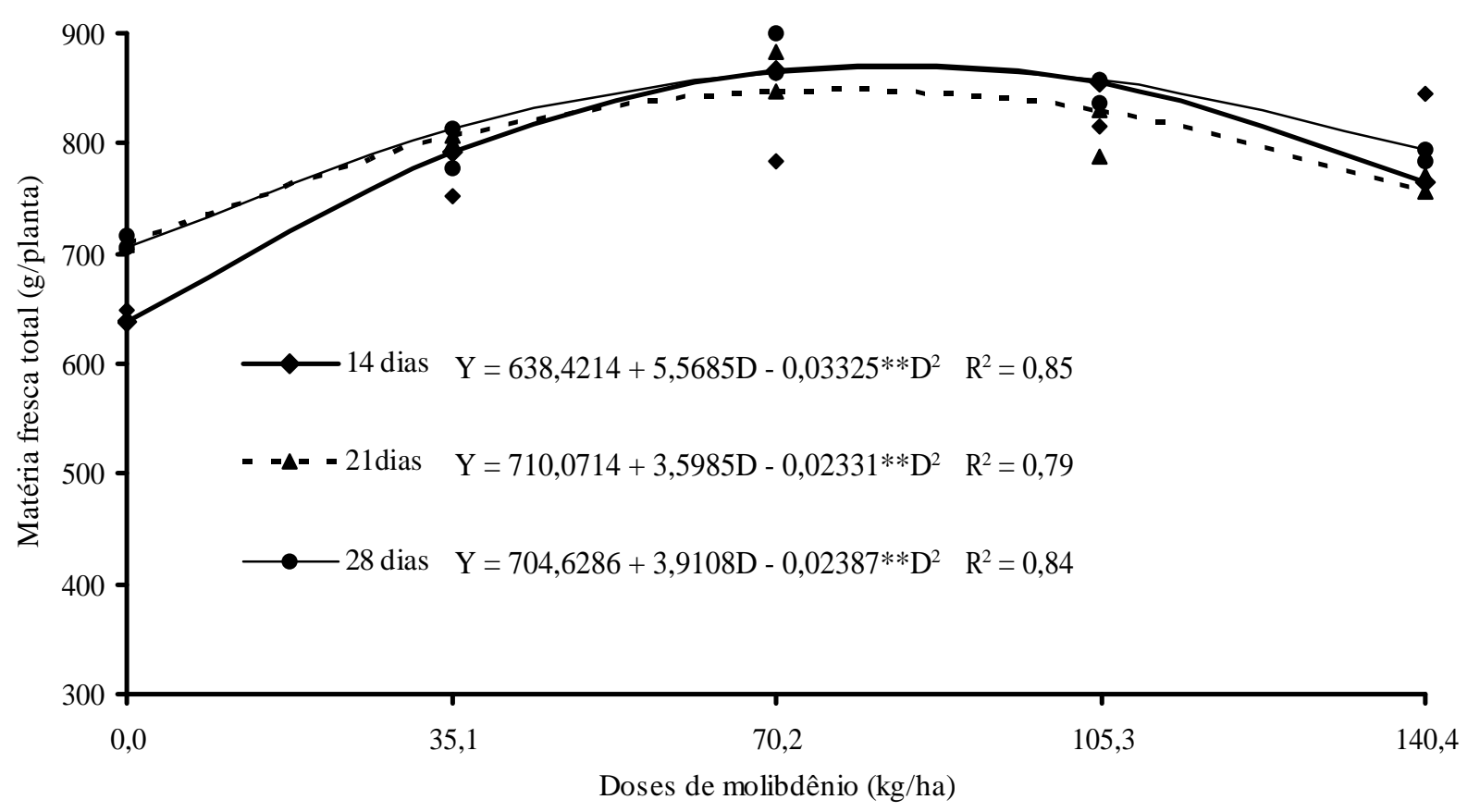

Figura 1 - Matéria fresca total da alface tipo americana de doses de molibdênio em função de épocas de aplicação. Três Pontas, MG, 2002. 


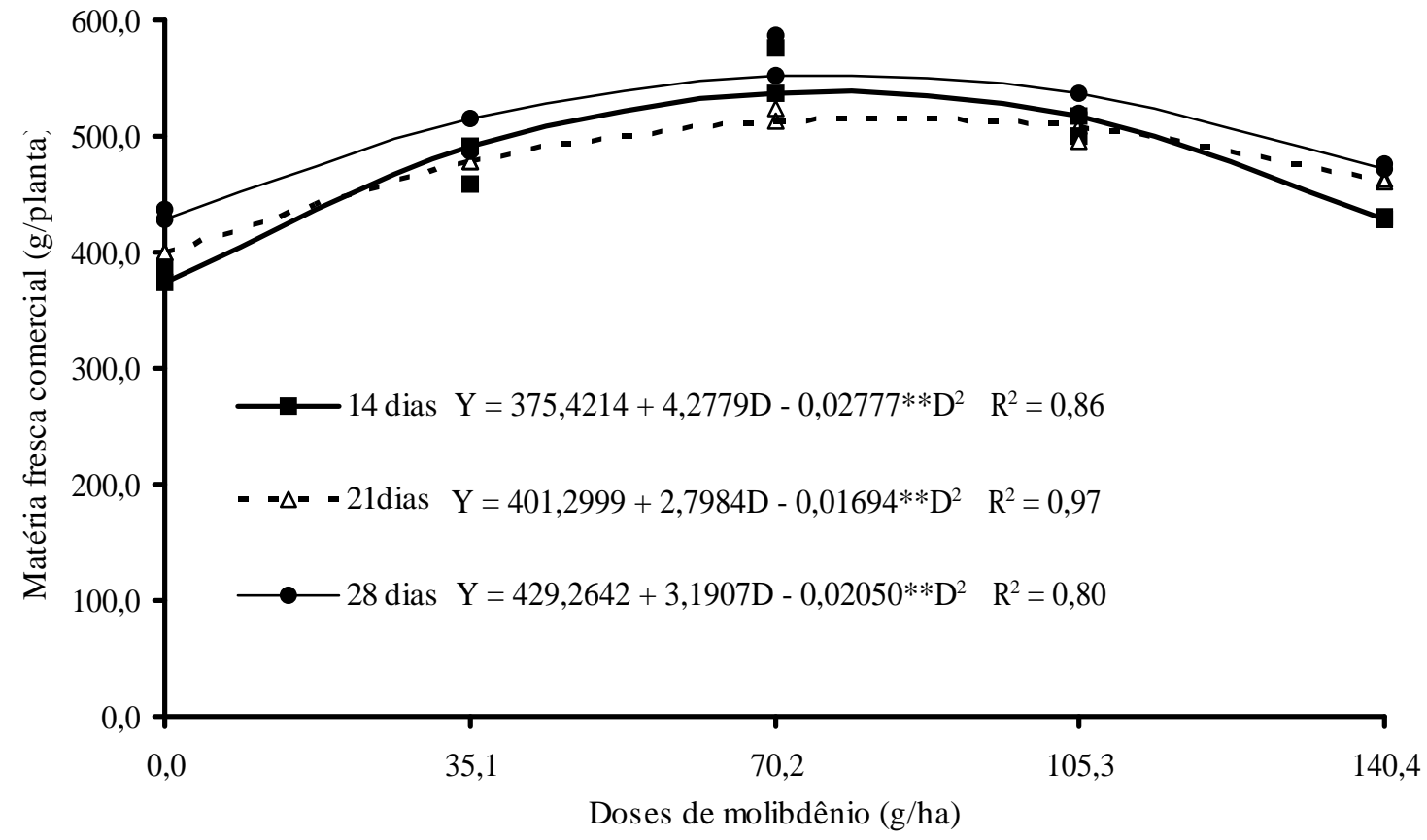

Figura 2 - Matéria fresca comercial da alface tipo americana de doses de molibdênio em função de épocas de aplicação. Três Pontas, MG, 2002.

94,2 g/ha de molibdênio proporcionado o maior rendimento. Resultados positivos da aplicação de molibdênio na cultura da alface foram também relatados por Fontes et al. (1982) e Zito et al. (1994), que observaram aumento médio de 31,0\% e $24,1 \%$, na produção comercial de alface com a aplicação de molibdênio. A resposta positiva à aplicação de molibdênio está relacionada provavelmente a sua função no metabolismo do nitrogênio, o qual está ligado à ação ou ativação enzimática, principalmente da enzima redutase do nitrato, pela redução e assimilação do nitrogênio pela planta (DECHEN et al., 1991; KAISER et al., 2005). Graham \& Stangoluis (2005) reafirmam o papel do molibdênio na redução e asssimilação do nitrogênio, relatando que a deficiência do elemento, promove reduções de crescimento que alteram o desenvolvimento da planta, além de tornarem as plantas mais suscetíveis ao ataque de pragas e doenças.

Para comprimento do caule (Figura 3) observou-se apenas efeito para doses de molibdênio $\left(\mathrm{F}_{(4,42)}=3,54\right.$; $\mathrm{P}<0,01406$ ), na qual a dose de $85,6 \mathrm{~g} /$ ha sobressaiu com maior comprimento que alcançou $3,17 \mathrm{~cm}$. Ao contrário, Resende et al. (2005) e Yuri et al. (2004) não observaram efeitos significativos do molibdênio no comprimento do caule da alface.

Menores comprimentos de caule são desejáveis para a alface americana, principalmente quando destinada à indústria de beneficiamento, devendo ser bastante reduzido, proporcionando menores perdas durante o processamento. O caule comprido acarreta menor compacidade da cabeça e dificulta o beneficiamento, afetando a qualidade final do produto (RESENDE et al., 2003). Na prática, caules com até $6,0 \mathrm{~cm}$ seriam os mais adequados, sendo aceitáveis até $9,0 \mathrm{~cm}$ e inaceitáveis ou menos recomendados para processamento acima disto. Neste contexto, as doses de molibdênio proporcionaram comprimentos entre 2,59 a $3,17 \mathrm{~cm}$, considerados adequados ao processamento.

A circunferência da cabeça comercial é uma importante característica para a alface tipo americana, considerando a preferência do consumidor para cabeças de maior tamanho na aquisição do produto. Esta característica não apresentou diferenças estatísticas entre as épocas de aplicação que obtiveram $42,7 \mathrm{~cm}$ (14 dias), $42,9 \mathrm{~cm}$ (21 dias) e 43,8 cm (28 dias) e entre doses de molibdênio que registraram variações de 42,2 a 44,6 cm. Yuri et al. (2004) não observaram diferenças significativas quando aplicaram aos 14 e 21 dias após o transplantio e Resende et al. (2005), observaram efeito significativo da aplicação de molibdênio, na qual a dose de $72,9 \mathrm{~g} / \mathrm{ha}$, proporcionou a maior circunferência da cabeça com 37,45 $\mathrm{cm}$, no entanto, em condições de verão. 


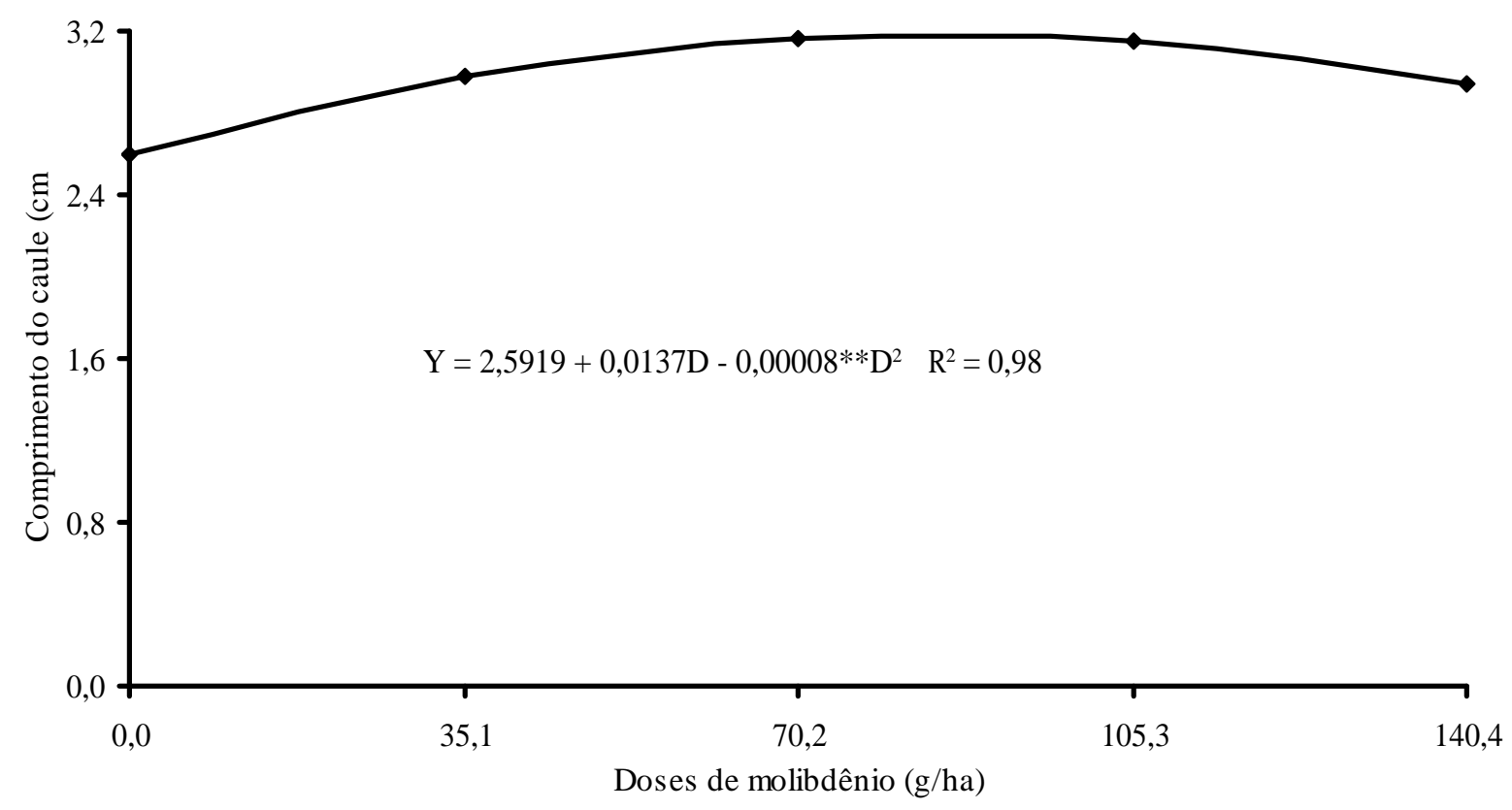

Figura 3 - Comprimento do caule da alface tipo americana em função das doses de molibdênio. Três Pontas, MG, 2002.

\section{CONCLUSÕES}

As doses de molibdênio foliar influenciaram positivamente a matéria fresca total, comercial e o comprimento do caule.

A circunferência da cabeça comercial da alface tipo americana não apresentou diferenças significativas entre os tratamentos.

A aplicação aos 28 dias após o transplantio proporcionou a maior produtividade de matéria fresca comercial na dose de $77,5 \mathrm{~g} / \mathrm{ha}$ de molibdênio.

\section{REFERÊNCIAS BIBLIOGRÁFICAS}

CASTELLANE, P. D.; SOUZA, A. F.; MESQUITA FILHO, M. D. de. Culturas olerícolas. In: FERREIRA, M. E.; CRUZ, M. C. P. da (Eds.). Micronutrientes na agricultura. Piracicaba: Potafos/CNPq, 1991. p. 549-584.

DECHEN, A. R.; HAAG, H. P.; CARMELLO, Q. A. de C. Funções de micronutrientes nas plantas. In: FERREIRA, M. E.; CRUZ, M. C. P. da (Eds.). Micronutrientes na agricultura. Piracicaba: Potafos/CNPq, 1991. p. 65-78.

EMPRESA BRASILEIRA DE PESQUISA AGROPECUÁRIA. Sistema brasileiro de classificação de solos. Brasília, DF, 1999. 412 p.
FAQUIN, V. Nutrição mineral de plantas. Lavras: UFLA/ FAEPE, 1997. $227 \mathrm{p}$.

FERREIRA, M. E.; CASTELLANE, P. D.; CRUZ, M. C. P. da. Nutrição e adubação de hortaliças. Piracicaba: Potafos, $1993.480 \mathrm{p}$.

FONTES, R. R.; LIMA, J. A.; TORRES, A. C.; CARRIJO, O. A. Efeito da aplicação de Mg, B, Zn e Mo na produção de alface. Pesquisa Agropecuária Brasileira, Brasília, v. 17, n. 2, p. 171-175, fev. 1982.

GRAHAM, R. D.; STANGOULIS, J. R. C. Molybdenum and disease. In: DANTOFF, L.; ELMER, W.; HUBER, D. (Eds.). Mineral nutrition and plant diseases. Saint Paul: APS, 2005. $214 \mathrm{p}$.

GUPTA, U. C.; LIPSETT, J. Molybdenum in soils, plants, and animals. Advances in Agronomy, New York, v. 34, p. 73-115, 1981.

HAMASAKI, R. I.; BRAZ, L. T.; GRILLI, G. V. G. Produção e avaliação de mudas de alface no sistema flutuante. In: CONGRESSO BRASILEIRO DE OLERICULTURA, 40., 2000, São Pedro, SP. Horticultura Brasileira, Brasília, v. 18 , p. 577-579, 2000. Suplemento. 
INSTITUTO BRASILEIRO DE GEOGRAFIA E ESTATÍSTICA. Organização do território: vilas e cidades. Disponível em: <http://www.Ibge.gov.br>. Acesso em: 19 set. 2005.

KAISER, B. N.; GRIDLEY, K. L.; BRADY, J. E.; PHILLIPS, T.; TYERMAN, S. D. The role of molybdenum in agricultural plant production. Annals of Botany, London, v. 96, n. 5, p. 745-754, 2005.

MAlaVolta, E.; KLIEMANN, H. J. Desordens nutricionais no cerrado. Piracicaba: Potafos, 1985. 136 p.

RESENDE, G. M. de; ALVARENGA, M. A. R.; YURI, J. E.; MOTA, J. H.; SOUZA, R. J. de; RODRIGUES JÚNIOR, J. C. Produtividade e qualidade pós-colheita da alface americana em função de doses de nitrogênio e molibdênio. Horticultura Brasileira, Brasília, v. 23, n. 4, p. 976-981, out./dez. 2005.

RESENDE, G. M. de; YURI, J. E.; MOTA, J. H.; SOUZA, R. J.; FREITAS, S. A. C.; RODRIGUES JÚNIOR, J. C. Efeitos de tipos de bandejas e idade de transplantio de mudas sobre o desenvolvimento e produtividade de alface americana. Horticultura Brasileira, Brasília, v. 21, n. 3, p. 562-567, jul./set. 2003.

ROSOlEM, C. A.; BOARETTO, A. E. (Eds.). Simpósio brasileiro de adubação foliar. Botucatu: FEPAF/UNESP, 1987. $575 \mathrm{p}$.

SONNENBERG, P. E. Olericultura especial: $1^{\mathrm{a}}$ parte: alface, cenoura, batata, tomate, cebola e alho. Goiânia: UFG, 1998. $184 \mathrm{p}$.

YURI, J. E.; RESENDE, G M.de; MOTA, J. H.; GONÇALVES, L. D.; SOUZA, R. J. Doses e épocas de aplicação de molibdênio na produção e qualidade de alface americana. Horticultura Brasileira, Brasília, v. 22, n. 3, p. 589-592, jul./set. 2004.

ZITO, R. K.; FRONZA, V.; MARTINEZ, H. E. P.; PEREIRA, P. R. G.; FONTES, P. C. R. Fontes de nutrientes, relações nitrato: amônio e molibdênio, em alface (Lactuca sativa 1.) produzida em meio hidropônico. Revista Ceres, Viçosa, v. 41, n. 236, p. 419-430, jul./ago. 1994. 